\title{
Clinical Social Work Practice in the Twenty-First Century: A Changing Landscape
}

\author{
Manny J. González ${ }^{1}$ Caroline Rosenthal Gelman ${ }^{1}$
}

Published online: 2 August 2015

(c) Springer Science+Business Media New York 2015

\section{Introduction}

Tensions within social work as to its organizing values, its primary objectives, and the optimal ways of achieving these can be found in its very origins as a profession in the U.S.: the settlement house movement with its focus on social change on the one hand, and charity service organizations with their emphasis on individual needs on the other. The confusion and reservations surrounding clinical social work have been particularly salient (Goldstein 1996, 2007; Phillips 2000; Specht and Courtney 1995; Swenson 1998). Compounding this seminal tension have been the questions raised both within and from outside the field and answered in the negative by Abraham Flexner (2001) exactly 100 years ago as to whether social work is, indeed, a profession. As we reflect on social work's past century of existence and efforts at professionalization in our own and others' eyes, (Gibelman 1999; Kerson and McCoyd 2013) this historical marker seems an apt moment to examine direct social work practice and the political, economic, geographic, social, cultural and philosophical forces shaping it in the twenty first century.

In this special issue of the Clinical Social Work Journal we ask leading social work practitioners, researchers, and educators to consider where we are as a field, where we are headed, what has been gained and what has been lost by current conceptualizations of clinical social work practice. In having ten eminent voices speaking from different positions within our multifarious field- academia (field

Manny J. González

mgo0026@hunter.cuny.edu

1 Silberman School of Social Work at Hunter College, City University of New York, New York, USA educators, classroom educators and students), research, community-based organizations, private practice-we hope to spark a productive national dialogue among clinical practitioners; students, academics and higher education administrators; field instructors, clinical preceptors and supervisors; clinical researchers; policy makers; executive directors and senior management of treatment and human service organizations; and professional membership organizations that will stimulate rich discussion about social work's past, present and future.

\section{Definition of Clinical Social Work: A Historical and Contemporary Perspective}

From a historical perspective, clinical social work practice and treatment is rooted in the casework method of the profession. Casework was the designated term for the delivery of direct psychosocial services to individuals and families (see Woods and Hollis 2000). According to Strean (1978), casework has been identified within the social work literature as the oldest and most prevalent helping method in the profession. Based on specific clinical social work treatment approaches, such as Pearlman's (1957) problemsolving model, Hamilton's (1951) and Hollis' (1964) psychosocial model, and Smalley's (1967) functional model, the primary historical aim of casework intervention was to restore, enhance or maintain the socio-emotional functioning of individuals and families who were experiencing distress at an intrapersonal, interpersonal or environmental level. Informed by the nineteenth century principles of scientific philanthropy, casework-as a helping method within the profession of social work-was first conceptualized and codified by Mary Richmond (1917) in Social Diagnosis. 
In this classic book, Richmond (1917) outlined the helping process that would eventually illuminate the diagnostic and treatment procedures of clinical social work practice. The outline included the steps required to collect data on an identified client's level of psychosocial functioning and how this information could be used to develop inferences that would give direction to the development of a social diagnosis and social treatment plan for the identified client system. Richmond's $(1917,1922)$ emphasis on the social functioning of individuals - as noted in her use of the terms social diagnosis and social treatment-draws attention to the fact that the early origins of clinical social work practice clearly underscored the importance of an individual's environment and interpersonal relationships in either exacerbating or ameliorating problems-in-living and psychosocial stress. In support of the social reform movement of the nineteenth and early twentieth centuries (see Trattner 1999), Richmond (1917) noted that the optimal functioning of society and individuals were clearly interrelated. Her seminal writings (see Richmond 1917, 1922, 1930) provide evidence for a type of clinical social work treatment and practice that views the personality of the human organism as a by-product of past and present experiences, family history and the influence of environmental factors. Richmond is eloquent on this point:

When we put "social" in front of [the word environment,]... the environment ceases to be environment in space merely - it widens to the horizon of man's thought, to the boundaries of his capacity for maintaining relationships, and it narrows to the exclusion of all things which have no real influence upon his emotional, mental, and spiritual life...1922, p. 99.

At a time in its history in which social work was in a quest for professionalization (see Trattner 1999), Mary Richmond continued to systematize casework practice-the forerunner of clinical practice with individuals and families-by writing What Is Social Casework? An Introductory Description, in 1922. In this book Richmond advanced the conceptual thinking and treatment strategies that were necessary for the psychosocial care of vulnerable individuals and families. Predicated on her conviction that individual treatment without environmental manipulation was not always effective and convinced that social and family factors do impact psychological functioning, Richmond (1922) identified the following two major interventions that would become the pillars of clinical social work practice: indirect treatment and direct treatment. Indirect treatment was aimed at reducing environmental strain or pressure and increasing personal functioning by linking clients to family or social/community resources. Direct treatment or "direct action of the practitioner's mind upon the mind of the client" (Richmond 1922, pp. 101-102) provided the client with insight into his or her individual characteristics and assisted the client with reorganizing thinking patterns that were contributing to psychosocial distress and maladaptive coping. Direct treatment was often implemented through the use of professional suggestions and advice. These two noted treatment procedures foreshadowed a model of clinical social work treatment that would need to take into account both the internal and external worlds of individuals within the context of a helping encounter in which the client-clinician relationship would serve as a major medium for therapeutic change.

The field [of social casework] is the development of personality through the conscious and comprehensive adjustment of social relationships, and within that field the worker is no more occupied with abnormalities in the individual than in the environment, is no more able to neglect the one than the other. The distinctive approach of the caseworker, in fact, is back to the individual by way of his social environment, and wherever adjustment must be effected in this manner, individual by individual, instead of in the mass, there some form of social case work is and will continue to be needed. So long as human beings are human and their environment is the world, it is difficult to imagine a state of affairs in which both they and the world they live in will be in no need of these adjustments and readjustments....p. 98.

Mary Richmond's approach to the psychosocial care of distressed individuals and families has often been linked to a "medical model" of social work treatment because of its emphasis on a social study, diagnosis and treatment planning process that was predicated on the collection of psychosocial data from an identified client that would assist the practitioner in uncovering the etiology of the client's presenting problem and a corresponding social cure (see Gitterman 2014). McLaughlin (2002), however, has noted that Richmond's application of the medical model to the provision of casework treatment must be understood within an historical era in which she-as a social work pioneerwas attempting to find a credible and scientific base for social casework as a recognized and societally-sanctioned helping method. Richmond's identification with the medical profession and a medical model of social care did not minimize her concern for societal improvement and the eradication of the complex social ills of her time such as poverty, alcoholism and unemployment. In Social Diagnosis Richmond (1917) underscores the need for clinical practitioners to comprehensively study the environmental factors that impinge on individuals and families and, therefore, on every case that requires psychosocial intervention. Woods and Hollis (2000), in highlighting 
Richmond's contribution to clinical social work practice, state that: "If Richmond's balanced 'person-in-situation' perspective had remained in the forefront of [social work practice] theory through the years, the tendency for social work's pendulum to swing from one extreme to another [individual treatment versus social reform] might have been avoided" (p. 10).

The first thorough definition of clinical social work practice was developed by the National Association of Social Workers' [NASW] Task Force on Clinical Social Work Practice in 1978 (see Cohen 1980). The task force was charged with birthing a definition that would provide the impetus for engagement and dialogue between NASW and those within its membership body that identified as clinical practitioners. It was convened a few years after the establishment of the National Federation of Societies for Clinical Social Work in 1971 and the founding of the Clinical Social Work Journal in 1973 (see Strean 1978). After significant deliberation, the task force proposed the following definition of clinical social work practice:

The practice of clinical social work involves a wide range of psychosocial services to individuals, families, and small groups in relation to a variety of human problems in living. Such practice may be carried out under both private and public auspices. It is concerned with the assessment of interaction between the individual's biological, psychological, and social experience, which provides a guide for clinical intervention. One of the distinguishing features of clinical social work, as compared with other kinds of clinical interventions, is the clinician's concern with the social context within which individual or family problems occur and are altered. Clinical social work, therefore, may involve intervention in the social situation as well as the person situation. Intervention in both the social situation and the person situation are valued approaches in clinical social work practice. At least three major principles by which clinical social work produces change or maintenance of function can be identified. Such goals can be reached through the interpersonal relationship with the clinician; they can be brought about through alterations in the social situation; and they can be brought about through alterations of relationships with significant persons in the life space of the individual. Personal satisfaction and improved social functioning are both important ends; neither can be ignored or imputed to be of shallow consequence (Cohen 1980, p. 26).

Prior to the development and adoption of the above definition of clinical social work practice, NASW-via the publication of its first Register of Clinical Social Workers-had identified the primary role and function of a clinical social work practitioner, underscored the range of organizational settings in which clinical social work might be practiced, and highlighted a practice framework for assessment, diagnosis and treatment planning (see NASW 1976). The Register defined a clinical social worker as one who is: "by education (at the master's or doctoral degree level) and experience, professionally qualified at the autonomous practice level to provide direct, diagnostic, preventive and treatment services to individuals, families and groups where functioning is threatened or affected by social and psychological stress or health impairment" (NASW 1976, p. xi). Public, voluntary, for-profit, and private practice settings were identified as institutions in which clinical social workers might address an array of psychosocial concerns ranging from-but not limited toeconomic distress, health and disease, criminal justice and problems in daily living. The Register further noted a helping approach that was informed by a mutual clientpractitioner problem identification process and was predicated on an understanding of clients' strengths, personality dynamics and historical data, and the use of clients' adaptive coping capacities and community/environmental resources in achieving therapeutic change and progress.

Advancements in social and behavioral science theory and research, the development of graduate degree-granting social work programs in the United States, the institutionalization of social and clinical programs following the adoption of the Social Security Act in 1935, the positive outcomes of civil, anti-poverty and human right movements, and the continuous evolution of clinical practice (see Dorfman 1996; Goldstein 2007; Trattner 1999), created the necessary scientific, professional, educational, socio-economic, and political conditions for the expansion and deepening of Richmond's social casework treatment method. In this context, this helping method has transformed from a friendly visiting volunteer approach, to a paid and professionally recognized specialty within social work, which can take place within the context of human service organizations and/or private practice. These noted advancements provided the conceptual foundation for the most recent and comprehensive definition of clinical social work practice as articulated by the Council on Social Work Education (2009, p. 2):

As a specialty within the practice of social work, clinical social work builds on professional values, ethics, principles, practice methods, and the personin-environment perspective of the profession. It reflects the profession's mission to promote social and economic justice by empowering clients who experience oppression or vulnerability. Clinical social work requires the professional use of self to restore, maintain, and enhance the biological, 
psychological, social, and spiritual functioning of individuals, families, and groups. The practice of clinical social work requires the application of advanced clinical knowledge and clinical skills in multidimensional assessment, diagnosis, and treatment of psychosocial dysfunction, disability, or impairment including emotional, mental, and behavioral disorders, conditions, and addictions. Clinical practice interventions include case formulation based on differential diagnosis and assessment of risks and vulnerabilities and those factors that produce and constrain the strengths and resilience found in the transactions among people, their communities, and the larger social environment. Treatment methods include the provision of individual, family, and group work. Clinical social workers are engaged in crisis intervention, brief and long-term psychotherapy and counseling, client-centered advocacy, consultation, and evaluation. Interventions responsive to all dimensions of diversity are applied within the context of the therapeutic relationship guided by best practices and evidence-based guidelines. Clinical supervision is an important feature of clinical social work in agencies, organizations, and private practice settings.

This definition is not only consistent with the central aim of clinical social work treatment: the maintenance and enhancement of the psychosocial functioning of individuals, families and small groups via the provision of intrapersonal, interpersonal and environmental-societal resources, but it also acknowledges the complexity of the human organism and the social context that-in a transactional manner-impacts the human condition in an ongoing way (Gitterman and Germain 2008; Woods and Hollis 2000). Further, clinical social work practice as defined historically by the National Association of Social Workers and most recently by the Council on Social Work Education (see Cohen 1980; CSWE 2009) is significantly aligned with the profession's primary mission as noted in the discipline's Code of Ethics:

The primary mission of the social work profession is to enhance human well-being and help meet the basic human needs of all people, with particular attention to the needs and empowerment of people who are vulnerable, oppressed, and living in poverty. A historic and defining feature of social work is the profession's focus on individual well-being in a social context and the well-being of society. Fundamental to social work is attention to the environmental forces that create, contribute to, and address problems in living (NASW 2008, p. 1).

\section{Clinical Social Work Practice's Changing Landscape: Context and Process}

Clinical social work practice continues to evolve as a result of socio-political and economic changes, knowledge development, educational and scientific advances, and critical evaluation by social work practitioners, researchers, and scholars. Our contributors offer a contemporary view of clinical practice and clinical social work treatment across three significant and interrelated domains: (1) knowledge and skill acquisition, (2) organizational and social context, and (3) educational issues and concerns.

In the first section, Contemporary Knowledge Base, we find two articles. In the first, "What Clinical Social Workers Need to Know: Bio-psycho-social Knowledge and Skills for the twenty first century", Joan Berzoff and James W. Drisko, describe changes in clinical training in the past 15 years which, in consequence, have tended to degrade clinical practice. They consider the complex mental health needs of the twenty first century and the type of training social workers will need to have in order to competently meet these needs. The second paper in this section, "Evidence-Based Practice in Social Work: A Contemporary Perspective", by Melissa D. Grady and James W. Drisko offers an overview of evidence-based practice (EBP) in contemporary social work settings. Drs. Grady and Drisko argue that empirically supported treatments (ESTs)-treatment 'products'- are often confused with EBP, a process with four dimensions fully compatible with social work values and practice. Social workers need to understand this difference and educate administrators and policy-makers in settings were ESTs are being used without acknowledging clients' context or preferences.

The second group of articles are part of a section entitled Organizational and Work Context for Clinical Practice. Mimi Abramowitz' and Jennifer Zelnick's "Privatization in the Human Services: Implications for Direct Practice" provides a historical overview of the stages of privatization-marketization, managerialism, and financialization-which have so significantly impacted agencies, practitioners, and clients. Such forces render social services as commodities, and privilege efficiency, performance and accountability over mission, community roots and professional skills. Social workers in human services organizations directly experiencing such changes articulate the impact on their work, their clients' experience and the future of social service organizations.

The second paper in this section, by Thomas Brauner, "Contemporary Clinical Practice: A Private Practitioner's Perspective", counters the common sentiment that private practice is a repudiation of social work's values and mission. Given the economic and quality-of-life constraints in 
today's agency practice, Dr. Brauner argues that private practice is developmentally and professionally an important option for social workers, and one that is congruent with the profession's values. Far from private social work practitioners forsaking the field's mission, it may well be the profession itself that has abandoned these clinicians.

Our third section, Clinical Social Work in the Academy, offers perspectives on the current relationship between clinical social work and education in doctoral-level training, as it plays out in social work's signature pedagogy of field education, and from the perspective of a recent MSW graduate. Jeane W. Anastas, in her paper entitled "Clinical Social Work, Science, and Doctoral Education: Schisms or Synergy?" reports on recent trends in doctoral education. As the training ground for many of the full-time professors teaching the over 100, $000 \mathrm{BSW}$ and MSW students working towards their social work degrees in a given year in the United States (CSWE 2013) these educators' practice experience as well as their conceptualization of clinical social work will significantly impact front line social workers and the clients they serve. Dr. Anastas reports on the schism created for social work practitioners by the profession's increasing emphasis on research in an effort to claim a scientific base. Dr. Anastas argues for the creation of synergy between science and clinical social work, as befits a profession which is truly both a science and an art.

A second paper in this section, "The DSW: From skeptic to convert" by Bruce A. Thyer, traces the author's evolution from viewing the DSW degree as lesser than a Ph.D. to recognizing its value and significant contribution to maintaining clinical experience and excellence in classrooms training the next generation of social workers. This re-thinking of entrenched views and openness to consider alternatives is the outcome we hope to generate in sparking this dialogue about the past, present, and future of clinical social work.

In her paper entitled "Field education for clinical social work practice: Best practices and contemporary challenges" Marion Bogo describes the crisis that many field educators are experiencing in the implementation of best pedagogical practices for students due to reduced agency resources and increasing competition for quality field placements. Professor Bogo reviews the growing evidencebase for the critical role of field education in preparing future social workers for ethical, effective and competent practice. Because the proper training of this workforce is so critical to all stakeholders-social work educators, service organizations, governments, the public at large-Professor Bogo offers the hope that all these participants will engage in meaningful, synergistic collaboration to develop innovative responses to current challenges.

We conclude with the perspective of a voice for the future of our field, Geoffrey M. Golia, a recent MSW graduate writing "On the importance of direct practice experience among clinical social work faculty: A recent graduate's perspective". Mr. Golia presents recent research on the decline of full-time faculty with any social work practice experience and critically explores what this meant for him in his own training and currently as a fledgling social work practitioner. A further consideration, of course, is the ultimate impact of this on clients and the quality of services.

In the epilogue of this special issue we synthesize challenges and opportunities for clinical social work practice today, and pull together recommendations from these leading voices to envision a robust, dynamic future for clinical social work practice. It is our hope that this special issue of the Clinical Social Work Journal will indeed spark a productive national dialogue among clinical practitioners; academics and higher education administrators; field instructors, clinical preceptors and supervisors; clinical researchers; executive directors and senior management of treatment and human service organizations; and professional membership organizations directed at safe-guarding, embracing, redefining and solidifying the critical contribution of clinical social work practice in promoting the biopsycho-social well-being of diverse client populations.

Acknowledgment We would like to extend our gratitude to James McBride, MSW. He served as our Research Assistant, and his contribution was invaluable in bringing this project to completion. Mr. McBride recently received his MSW degree in Clinical Practice with Individuals and Families from the Silberman School of Social Work at Hunter College, City University of New York. He is now employed as a clinician at a community-based counseling clinic.

\section{References}

Cohen, J. (1980). Nature of clinical social work. In P. L. Ewalt (Ed.), Toward a definition of clinical social work (pp. 23-32). Washington, DC: National Association of Social Workers.

Council on Social Work Education. (2009). Advanced social work practice in clinical social work practice. Washington, DC: Council on Social Work Education.

Council on Social Work Education. (2013). 2013 Statistics on Social Work Education in the United States. Washington, D.C.: Council on Social Work Education.

Dorfman, R. A. (1996). Clinical social work: Definition, practice and vision. New York: Brunner/Mazel.

Flexner, A. (2001). Is social work a profession? Research on Social Work Practice, 11(2), 152-165.

Gibelman, M. (1999). The search for identity: Defining social workpast, present, future. Social Work, 44(4), 298-310.

Gitterman, A. (2014). Social work: A profession in search of its identity. Journal of Social Work Education, 50(4), 599-607.

Gitterman, A., \& Germain, C. B. (2008). The life model of social work practice (3rd ed.). New York: Columbia University Press.

Goldstein, E. (1996). What is clinical social work? Looking back to move ahead. Clinical Social Work Journal, 24, 89-104.

Goldstein, E. G. (2007). Social work education and clinical learning: Yesterday, today, and tomorrow. Clinical Social Work Journal, $35,15-23$. 
Hamilton, G. (1951). Theory and practice of social casework. New York: Columbia University Press.

Hollis, F. (1964). Casework: A psychosocial therapy. New York: Random House.

Kerson, T. S., \& McCoyd, J. L. (2013). In response to need: An analysis of social work roles over time. Social Work, 58(4), 333-343.

McLaughlin, A. M. (2002). Social work's legacy: Irreconcilable differences? Clinical Social Work Journal, 30(2), 187-200.

National Association of Social Workers. (1976). Register of clinical social workers. Washington, DC: National Association of Social Workers.

National Association of Social Workers. (2008). Code of ethics of the National Association of Social Workers. Washington, DC: National Association of Social Workers.

Pearlman, H. H. (1957). Social casework: A problem solving approach. Chicago: Chicago University Press.

Phillips, D. G. (2000). CSWJ forum: Is clinical social work a profession? Preliminary Considerations. Clinical Social Work Journal, 28(2), 213-225.

Richmond, M. E. (1917). Social diagnosis. New York: Russell Sage Foundation.

Richmond, M. E. (1922). What is social casework?An introductory description. New York: Russell Sage Foundation.

Richmond, M. E. (1930). The long view. New York: Russell Sage Foundation.

Smalley, R. E. (1967). Theory for social work practice. New York: Columbia University Press.
Specht, H., \& Courtney, M. E. (1995). Unfaithful angels: How social work has abandoned its mission. New York: Simon and Schuster.

Strean, H. S. (1978). Clinical social work: Theory and practice. New York: Free Press.

Swenson, C. (1998). Clinical social work's contribution to a social justice perspective. Social Work, 43(6), 527-537.

Trattner, W. I. (1999). From poor law to welfare state: A history of social welfare in America. New York: The Free Press.

Woods, M., \& Hollis, F. (2000). Casework: A psychosocial therapy (5th ed.). New York: McGraw-Hill.

Dr. Manny J. González is an Associate Professor at the Silberman School of Social Work at Hunter College and the Graduate Center, City University of New York (Ph.D. Program in Social Welfare) where he teaches graduate courses in clinical practice, relational therapy, psychopathology, and evidence-based mental health practice. He has practiced as a clinician for 30 years specializing in community mental health. Dr. González maintains a private practice in psychodynamic psychotherapy and clinical supervision in Brooklyn Heights, New York.

Dr. Caroline Rosenthal Gelman is an Associate Professor and Director of the MSW Program at the Silberman School of Social Work at Hunter College. She has practiced as a clinical social worker for 24 years, specializing in mental health issues in community settings and with diverse populations. 